CLINICAL STUDY

\title{
High IGFBP2 levels are not only associated with a better metabolic risk profile but also with increased mortality in elderly men
}

\author{
Annewieke W van den Beld ${ }^{1,2}$, Werner F Blum ${ }^{3,4}$, Michael P Brugts ${ }^{1}$, Joop A M J L Janssen ${ }^{1}$, \\ Diederick E Grobbee ${ }^{5}$ and Steven W J Lamberts ${ }^{1}$ \\ ${ }^{1}$ Department of Internal Medicine, Erasmus MC, Rotterdam, The Netherlands, ${ }^{2}$ Department of Internal Medicine, Groene Hart Ziekenhuis, \\ Bluelandweg 10, 2803 HH Gouda, The Netherlands, ${ }^{3}$ Lilly Research Laboratories, Lilly Deutschland, Bad Homburg, Germany, ${ }^{4}$ University Children's \\ Hospital, Giessen, Germany and ${ }^{5} J u l i u s$ Center for Health Sciences and Primary Care, University Medical Center Utrecht, Utrecht, The Netherlands \\ (Correspondence should be addressed to A W van den Beld at Department of Internal Medicine, Groene Hart Ziekenhuis; \\ Email: annewieke.van.den.beld@ghz.nl)
}

\begin{abstract}
Objective: Serum IGF-binding protein 2 (IGFBP2) concentrations are reduced in obese humans and increase after a prolonged period of fasting. We investigated the association between IGFBP2 levels and mortality together with other factors that are related to IGFBP2, including the metabolic syndrome and physical function.

Design: A prospective observational study at a clinical research center of 403 independently living elderly men (aged 73-94 years).

Methods: Mortality was registered during 8.6 years of follow-up. Physical performance score (PPS), grip strength (GS), and bone mineral density (BMD) were measured. The measurements taken a baseline were: IGF1; IGFBP1, -2, and -3; IGF1 bioactivity; triiodothyronine $\left(\mathrm{T}_{3}\right)$; and reverse $\mathrm{T}_{3}$. Further, BMI, insulin sensitivity, cholesterol, inflammatory markers, and albumin levels were also measured.

Results: During the follow-up, 180 men died. Higher PPS, GS, and BMD were independently related to a reduced mortality (hazard ratio $(\mathrm{HR})=0.87 /$ point, $95 \%$ confidence interval $(95 \% \mathrm{CI})=0.82-0.91$, $P<0.001 ; \mathrm{HR}=0.96 / \mathrm{kp}, 95 \%$ CI $0.94-0.98, P<0.001$; and $\mathrm{HR}=0.21 /\left(\mathrm{g} / \mathrm{cm}^{2}\right), 95 \%$ CI $0.07-0.61$, $P<0.01)$. Higher serum IGFBP2 levels were strongly related to mortality (HR $=2.26 /(\mathrm{mg} / \mathrm{l}), 95 \%$ CI 1.57-3.27, $P<0.001)$. This was independent of comorbidity, physical function, IGF1 bioactivity, and other somatotropic parameters, including BMI and the metabolic syndrome. In addition, IGFBP2 levels were higher in subjects with nonthyroidal illness, and higher IGFBP2 levels were significantly associated with lower albumin concentrations.

Conclusion: Despite the strong relationship between high IGFBP2 and low physical function, both were strongly and independently related to increased 8-year mortality in elderly men. IGFBP2 may be a useful biomarker integrating the nutritional status, as well as the biological effects of GH, IGF1, and insulin.
\end{abstract}

European Journal of Endocrinology 167 111-117

\section{Introduction}

Aging is associated with several changes in the somatotropic axis. Serum GH, insulin-like growth factor 1 (IGF1), and IGF-binding protein 3 (IGFBP3) levels decrease with age, while IGFBP1 and -2 levels increase. It is unclear whether the physiological decrease in GH and IGF1 levels with age represents a symptom of declining neuroendocrine function, a cause of age-related alterations in body composition and functionality, or a protective mechanism against age-associated disease. Low IGF1 signaling prolongs life span in certain animal models $(1,2)$. However, we recently described that a relatively high circulating IGF1 bioactivity in elderly men is associated with extended survival and reduced cardiovascular risk (3).

The biological actions of IGFs are modulated by a family of IGFBPs (4). They serve as carriers of IGF, prolong IGF half-life in the circulation, and modulate IGF activity at the cell surface receptors $(5,6)$. In addition, IGFBPs may also mediate IGF-independent effects on the cell surface $(7,8,9,10,11)$.

Previously, we demonstrated a relationship between high serum IGFBP2 levels and a low physical performance in aging men (12). The physiological role of IGFBP2 is less well known, but more data have 
become available on the regulation and role of IGFBP2. Serum IGFBP2 concentrations are reduced in obese humans (13) and do increase after a prolonged period of fasting (14). In a cohort of patients with type 2 diabetes, low IGFBP2 concentrations were associated with the presence of metabolic syndrome and cardiovascular risk factors (15). Wheatcroft et al. (16) demonstrated that IGFBP2-overexpressing mice were protected against age-related decline in glucose tolerance and insulin sensitivity. In line with these observations, in a brief report, Hu et al. (17) demonstrated that higher IGFBP1 and -2 levels were associated not only with lower adiposity and increased glucose tolerance but also with greater all-cause mortality in a population of 625 older men and women.

Considering these apparently contradictory effects of IGFBP2, we examined the relationship between IGFBP 2 concentrations and mortality in a population of healthy elderly men. In addition, we investigated its relationship with physical function, bioactive IGF1, and the metabolic syndrome.

\section{Materials and methods}

\section{Subjects}

The design of the Zoetermeer study, a prospective cohort study conducted in clinically healthy, independently living Caucasian elderly men, has been reported previously (18). At baseline, 1567 men aged 70 years and older were invited based on the addresses drawn from the municipal register of a medium-sized town in The Netherlands. Eight hundred and eighty six men did not respond to the mailed invitation in which it was mentioned that only subjects who lived independently and had no severe mobility problems could participate. Ultimately, $403(25.7 \%)$ men participated and gave written informed consent. The Medical Ethics Committee of the Erasmus University Hospital, Rotterdam, approved the study.

At baseline, medical histories were obtained from all participants. General practitioners were contacted about the status of the participants in the subsequent years. Cause of death was derived from death certificates and could only be verified in a limited number of subjects. The maximum follow-up time was 8.6 years. Information on nonfatal events was not registered.

\section{Anthropometric measurements}

Height and weight were measured. Systolic blood pressure (SBP) and diastolic blood pressure (DBP) were measured in duplicate. Body mass index (BMI) was calculated as the weight in kilograms divided by the square of the height in meters.

\section{Physical characteristics}

Physical performance Lower extremity function, or physical performance, was assessed as described by Guralnik et al. (19, 20), including measurements of standing balance, walking speed, and ability to rise from a chair. A summary performance scale was created by summing the category scores for walking, chair stand, and balance test, which ranged from 0 (worst performance) to 12 (best performance).

Muscle strength Isometric grip strength (IGS) was tested using an adjustable hand-held dynamometer (JAMAR dynamometer) in the nondominant hand (21). Each test was repeated three times and the average, expressed in kiloponds (kp), was used in the analysis.

Bone mineral density and body composition Total body bone mineral density (BMD) was measured using dual-energy X-ray absorptiometry (DXA; Lunar, Madison, WI, USA); similarly, hip BMDs at the femoral neck, trochanter, and Ward's triangle were also measured. In addition, total and trunk lean body mass and fat mass were measured $(22,23)$. Quality assurance including calibration was performed routinely every morning for DXA, using the standard provided by the manufacturer. The mini mental state examination was used to estimate cognitive function (24).

\section{Assays}

Blood samples were collected in the morning after an overnight fast. Serum was separated by centrifugation and deeply frozen. Serum and plasma aliquots were stored at $-40{ }^{\circ} \mathrm{C}$ immediately after processing. An IGFBP-blocked RIA in the presence of large excess of IGF2 as described (25) determined the total IGF1. The intra- and interassay coefficients of variation (CV) were 1.6 and $6.4 \%$ respectively. IGFBP1, IGFBP2, and IGFBP3 were measured with in-house RIAs as described previously with intra-assay $\mathrm{CV}$ of $3.4,2.9$, and $1.9 \%$ and interassay $\mathrm{CV}$ of $8.1,10.3$ and $9.2 \%$ respectively (25). IGF1 bioactivity was measured using an in-house IGF1 KIRA as described previously (26). Intra- and interassay CV were 6.0 and $10.9 \%$ respectively.

Insulin was measured using a commercially available RIA (Medgenix Diagnostics, intra-assay and inter-assay CV: 8.0 and 13.7\%). Insulin sensitivity was calculated according to the homeostasis model assessment (HOMA) model 2 (HOMA Calculator version 2.2; Oxford Centre for Diabetes, Endocrinology and Metabolism). Glucose and $\mathrm{HbA1c}$ levels were measured by routine commercially available assays. Total and HDL cholesterol and triglycerides (TG) were measured using a commercially available kit (18). LDL cholesterol levels were calculated.

According to the criteria of the International Diabetes Federation, men were defined as having the metabolic 
syndrome if the waist-to-hip ratio (WHR) was $\geq 94 \mathrm{~cm}$ and two of the following factors were present: raised TG levels $\geq 1.7 \mathrm{mmol} / \mathrm{l}$ or specific treatment for this lipid abnormality; reduced HDL cholesterol $<1.03 \mathrm{mmol} / \mathrm{l}$ or specific treatment for this lipid abnormality; raised blood pressure (SBP $\geq 130 \mathrm{mmHg}$ or $\mathrm{DBP} \geq 85 \mathrm{mmHg}$ ) or specific treatment for previously diagnosed hypertension; raised fasting plasma glucose $\geq 5.6 \mathrm{mmol} / \mathrm{l}$; or previously diagnosed type 2 diabetes.

C-reactive protein (CRP) levels were determined by a highly sensitive CRP (hs-CRP) method using a latexenhanced immunonephelometric assay on a BM II analyzer (Dade Behring, Liederbach, Germany). Interleukin 6 (IL6) was measured according to the manufacturer's protocol using a commercially available Immulite assay (Diagnostic Products Corporation, Los Angeles, CA, USA). Albumin (g/l) was measured by photometry using a commercial kit (ALB; Boehringer, Mannheim, Germany). Triiodothyronine $\left(\mathrm{T}_{3}\right)$ and reverse $\mathrm{T}_{3}\left(\mathrm{rT}_{3}\right)$ were measured by RIA. Intra- and intervariability coefficients of the assays were below $11 \%$.

\section{Statistical analyses}

Results are expressed, unless otherwise indicated, as mean and S.D. with the 95\% confidence interval (95\% CI) range. Differences between survivors and non-survivors were evaluated using ANOVA with adjustment for age. Univariate general linear models were used to calculate the adjusted differences in means of variables between groups. Pearson $\chi^{2}$ test was used to test the significance between groups of frequencies.

Predictors of all-cause mortality were determined using Cox proportional hazards models, and ageadjusted hazard ratio estimates and 95\% CIs were calculated. The time-to-event variable was specified as time from baseline examination to death, as well as from follow-up time to death, denoted in months. IGFBP 2 was divided in quartiles and related to mortality risk using Cox regression modeling. In general, cause of death was based on death certificates that could not be verified in the majority of subjects. Therefore, cause of death was not controlled in all Cox proportional hazards models. Analyses were performed using SPSS version 15.0 for Windows, UK.

\section{Results}

\section{Baseline analyses}

The baseline characteristics of the participants, categorized as survivors $(n=223,55 \%)$ and non-survivors $(n=180,45 \%)$, are given in Table 1 . Mean age at baseline was 77.7 (range 73-94) years. Mean time to death was 81.9 (range 3-103) months.

At baseline, serum IGFBP2 concentrations were significantly inversely related to total IGF1 $(r=-0.15$, $P<0.01)$, IGF1 bioactivity $(r=-0.12, P<0.001)$, and IGFBP3 $(r=-0.28, P<0.001)$ and most strongly

Table 1 Baseline characteristics of 403 elderly men divided according to survival status 8 years after baseline.

\begin{tabular}{|c|c|c|c|}
\hline General characteristics & Mean (S.D.) & $\begin{array}{c}\text { Survivors } \\
(n=223 ; 95 \% \mathrm{Cl})\end{array}$ & $\begin{array}{l}\text { Non-survivors } \\
(n=180 ; 95 \% \mathrm{Cl})\end{array}$ \\
\hline Age (years) & $77.8(3.6)$ & $77.2(76.8 ; 77.6)$ & $78.6(78.0 ; 79.2)^{\dagger}$ \\
\hline Number of diseases ( 0 till $\geq 5$ ) & $2.73(1.72)$ & $2.40(2.18 ; 2.62)$ & $3.14(2.89 ; 3.39)^{\dagger}$ \\
\hline \multicolumn{4}{|l|}{ Physical characteristics } \\
\hline Physical performance (points) & $8.5(2.4)$ & $9.05(8.75 ; 9.35)$ & $7.70(7.35 ; 8.06)^{\dagger}$ \\
\hline Isometric grip strength $(\mathrm{kp})$ & $34.3(6.92)$ & $35.8(34.9 ; 36.7)$ & $32.5(31.6 ; 33.5)^{\dagger}$ \\
\hline \multicolumn{4}{|l|}{ Somatotropic hormones } \\
\hline IGF1 $(\mu \mathrm{g} / \mathrm{l})$ & $100.9(29.2)$ & $101.0(97.5 ; 104.5)$ & $100.7(96.0 ; 105.6)$ \\
\hline Bioactive IGF1 (pmol/l) & $333(133)^{\prime}$ & $344(328 ; 361)$ & $317(296 ; 337)$ \\
\hline IGF-binding protein $1(\mu \mathrm{g} / \mathrm{l})$ & $31.7(15.5)$ & $29.6(27.8 ; 31.4)$ & $34.4(31.8 ; 36.9)^{\star}$ \\
\hline IGF-binding protein 2 (mg/l) & $0.62(0.32)$ & $0.55(0.52 ; 0.58)$ & $0.71(0.65 ; 0.76)^{\dagger}$ \\
\hline IGF-binding protein 3 (mg/l) & $2.59(0.70)$ & $2.67(2.58 ; 2.77)$ & $2.48(2.38 ; 2.58)^{*}$ \\
\hline \multicolumn{4}{|l|}{ Metabolic parameters } \\
\hline BMI $\left(\mathrm{kg} / \mathrm{m}^{2}\right)$ & $25.4(3.0)$ & $25.6(25.2 ; 26.0)$ & $25.2(24.8 ; 25.7)$ \\
\hline Insulin (mU/l) & $8.91(4.25)$ & $8.67(8.11 ; 9.22)$ & $9.22(8.58 ; 9.86)$ \\
\hline Glucose $(\mathrm{mmol} / \mathrm{l})$ & $5.73(2.53)$ & $5.60(5.42 ; 5.78)$ & $5.89(5.38 ; 6.40)$ \\
\hline HOMA (\%S) & $98.8(45.7)$ & $101.6(95.4 ; 107.9)$ & $95.3(88.9 ; 101.8)$ \\
\hline $\mathrm{HDL}(\mathrm{mmol} / \mathrm{l})$ & $1.34(0.39)$ & $1.36(1.31 ; 1.41)$ & $1.32(1.26 ; 1.39)$ \\
\hline Triglycerides $(\mathrm{mmol} / \mathrm{l})$ & $1.39(0.84)$ & $1.39(1.27 ; 1.50)$ & $1.38(1.27 ; 1.39)$ \\
\hline Systolic blood pressure $(\mathrm{mmHg})$ & $156(24)$ & $156(153 ; 160)$ & $156(153 ; 160)$ \\
\hline Diastolic blood pressure (mmHg) & $84(11)$ & $84(83 ; 86)$ & $84(82 ; 85)$ \\
\hline \multicolumn{4}{|l|}{ Inflammatory markers } \\
\hline Albumin (g/dl) & $45.6(2.8)$ & $45.9(45.6-46.2)$ & $45.1(44.7-45.9)^{*}$ \\
\hline Interleukin 6 (pg/ml) & $191(110)$ & $174(159-189)$ & $212(197-227)^{\dagger}$ \\
\hline High sensitive CRP (mg/l) & $2.6(2.1)$ & $2.3(2.1-2.6)$ & $2.9(2.6-3.1)^{*}$ \\
\hline
\end{tabular}

${ }^{\star} P \leq 0.01,{ }^{\dagger} P \leq 0.001$. 
positively related to IGFBP1 $(r=0.52, P<0.001)$ levels. Higher IGFBP2 concentrations were related to a worse physical performance, GS, and BMD (all $P<0.01$ ).

Serum IGFBP2 levels were significantly lower in subjects with the presence of the metabolic syndrome (0.56 mg/l (95\% CI 0.51; 0.60) vs $0.67 \mathrm{mg} / \mathrm{l}$ (95\% CI $0.63 ; 0.71), P<0.001)$. The associations of IGFBP2 levels with a number of metabolic parameters are outlined in more detail in Table 2. In summary, after adjustment for age, lower serum IGFBP 2 concentrations were associated with an increased BMI and increased waist to hip ratio, higher triglyceride levels and lower HDL cholesterol, higher insulin levels and lower insulin sensitivity, and finally higher systolic and DBP. However, IGFBP2 levels did not differ between subjects with or without diabetes or with a history of cardiovascular disease.

No association was present between IGFBP2 concentrations and IL6 or hs-CRP levels. Further, IGFBP2 levels did not differ between subjects with a history of prostate cancer or other malignancy. Also, IGFBP 2 concentrations were not related to the number of diseases. Serum IGFBP2 was, on the other hand, significantly higher in subjects who met the criteria for low $\mathrm{T}_{3}$ syndrome $\left(\mathrm{T}_{3}\right.$ concentration below normal levels of young adults and $\mathrm{rT}_{3}$ concentrations above normal levels of young adults; $0.72 \mathrm{mg} / \mathrm{l}(95 \%$ CI $0.65 ; 0.80)$ vs $0.59 \mathrm{mg} / \mathrm{l}$ (95\% CI 0.56 ; 0.63$), P<0.001)$. Higher IGFBP2 levels were also associated with lower albumin levels (Table 2).

\section{Survival analyses}

At baseline, physical performance, isometric GS, and BMD were significantly higher in survivors. Serum IGFBP1 and IGFBP2 concentrations were significantly lower, while IGFBP3 concentrations were significantly higher in survivors. Finally, serum IL6 and hs-CRP were significantly lower in survivors. The metabolic parameters studied were not different between survivors or non-survivors (Table 1).
Survival analyses for quartiles of IGFBP2 were performed. Cox proportional hazard plots are shown in Fig. 1. Subjects with the highest IGFBP2 concentrations (fourth quartile) had a higher mortality risk $(\mathrm{HR}=1.98(95 \%$ CI 1.24-3.14)) compared with the reference group subjects with the lowest IGFBP2 concentrations (first quartile) after adjustment for age (Fig. 1).

As baseline IGFBP2 levels were strongly associated with physical performance, muscle strength, and $\mathrm{BMD}$, survival analyses were performed after adjustment for these parameters. Subjects with the highest IGFBP2 concentrations (fourth quartile) remained having a higher mortality risk compared with the reference group of subjects with the lowest IGFBP2 concentrations (first quartile) after adjustment for physical performance, IGS, and BMD (HR = 2.62 $(95 \%$ CI 1.23-5.58), $\mathrm{HR}=1.75$ (95\% CI 1.10-2.81), and $\mathrm{HR}=1.84$ (95\% CI 1.14-2.97) respectively). Also, lower physical performance, GS, and BMD remained independently related to mortality after adjustment for serum IGFBP2 concentrations $(\mathrm{HR}=0.87 /$ point (95\% CI 0.82-0.91), $P<0.001 ; \mathrm{HR}=0.96 / \mathrm{kp}(95 \% \mathrm{CI}$ $0.94-0.98), P<0.001$; and $\mathrm{HR}=0.21 /\left(\mathrm{g} / \mathrm{cm}^{2}\right)(95 \% \mathrm{CI}$ 0.07-0.61), $P<0.01)$.

The association between IGFBP2 and mortality also remained significant in a multivariate analysis including serum total IGF1, IGFBP1, and -3 concentrations. Higher IGFBP1 itself was related to a higher mortality, but lost its significant association after adjustment for IGFBP2 levels. IGFBP3 concentrations were higher in survivors compared with nonsurvivors, but this difference was no longer significant after adjustment for age. Higher BMI and lower insulin sensitivity were not associated with increased 8-year mortality.

Further, IL6, as well as hs-CRP and IGFBP2 concentrations remained independently related to 8 -year mortality in a multivariate model $(\mathrm{HR}=1.002 /(\mathrm{pg} / \mathrm{ml})$ (95\% CI 1.001-1.004), $P \leq 0.001 ; \mathrm{HR}=1.11 /(\mathrm{mg} / \mathrm{l})$

Table 2 Parameters of the metabolic syndrome and inflammatory parameters according to quartiles of IGFBP2 level, age adjusted.

\begin{tabular}{|c|c|c|c|c|}
\hline & \multicolumn{4}{|c|}{ IGFBP2 quartiles (95\% Cl) } \\
\hline & First $(0.06-0.40 \mathrm{mg} / \mathrm{l})$ & Second (0.40-0.57 mg/l) & Third $(0.57-0.76 \mathrm{mg} / \mathrm{l})$ & Fourth $(0.76-2.96 \mathrm{mg} / \mathrm{l})$ \\
\hline \multicolumn{5}{|c|}{ Metabolic and inflammatory parameters } \\
\hline BMI $\left(\mathrm{kg} / \mathrm{m}^{2}\right)$ & $27.0(26.4 ; 27.5)$ & $26.1(25.6 ; 26.7)$ & $24.9(24.3 ; 25.4)$ & $23.7(23.1 ; 24.2)^{\ddagger}$ \\
\hline WHR $(\mathrm{cm})$ & $100(99 ; 101)$ & $99(98 ; 100)$ & $97(96 ; 98)$ & $97(96 ; 98)^{\ddagger}$ \\
\hline Insulin (IU/I) & $10.9(10.0 ; 11.7)$ & $9.3(8.5 ; 10.1)$ & $8.1(7.3 ; 8.9)$ & $7.3(6.5 ; 8.1)^{\ddagger}$ \\
\hline Fasting glucose (mmol/l) & $6.0(5.5 ; 6.5)$ & $5.5(5.0 ; 6.0)$ & $5.6(5.1 ; 6.1)$ & $5.9(5.3 ; 6.4) \mathrm{NS}$ \\
\hline HOMA (\%S) & $77(68 ; 86)$ & $94(85 ; 102)$ & $105(96 ; 113)$ & $120(111 ; 129)^{\ddagger}$ \\
\hline $\mathrm{HDL}(\mathrm{mmol} / \mathrm{l})$ & $1.25(1.17 ; 1.32)$ & $1.33(1.25 ; 1.40)$ & $1.37(1.29 ; 1.44)$ & $1.43(1.35 ; 151)^{\dagger}$ \\
\hline Triglycerides (mmol/l) & $1.61(1.45 ; 1.78)$ & $1.57(1.41 ; 1.73)$ & $1.31(1.15 ; 1.46)$ & $1.05(0.89 ; 1.21)^{\ddagger}$ \\
\hline Systolic BP (mmHg) & $161(156 ; 166)$ & $158(153 ; 162)$ & $156(151 ; 161)$ & $151(146 ; 156)^{\star}$ \\
\hline Diastolic BP (mmHg) & $86(84 ; 88)$ & $85(83 ; 87)$ & $84(82 ; 86)$ & $81(79 ; 84)^{*}$ \\
\hline Albumin $(g / l)$ & $46.3(45.8 ; 46.8)$ & $46.1(45.6 ; 46.6)$ & $45.3(44.8 ; 45.9)$ & $44.6(44.0 ; 45.1)^{\ddagger}$ \\
\hline Interleukin 6 (pg/ml) & $185(163 ; 207)$ & $186(164 ; 209)$ & $190(169 ; 212)$ & $201(179 ; 224)$ NS \\
\hline $\mathrm{hs}-\mathrm{CRP}(\mathrm{mg} / \mathrm{l})$ & $2.9(2.5 ; 3.4)$ & $2.3(1.9 ; 2.7)$ & $2.7(2.2 ; 3.1)$ & $2.6(2.2 ; 3.0) \mathrm{NS}$ \\
\hline
\end{tabular}

${ }^{\star} P \leq 0.05,{ }^{\dagger} P \leq 0.01,{ }^{\ddagger} P \leq 0.001$. 


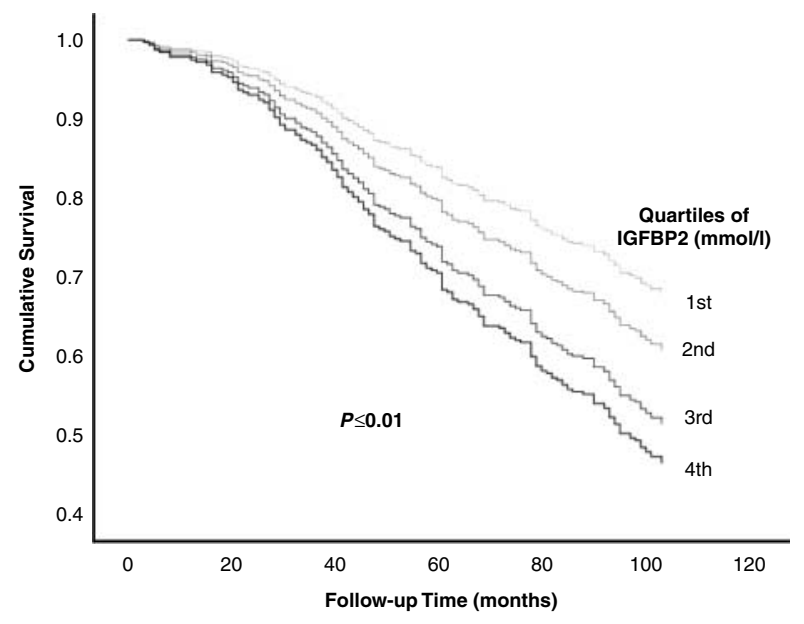

Figure 1 Survival curves showing the relationship between overall survival and IGFBP2 concentrations. $P$ value denotes the significance between the first and the fourth quartiles. Zoetermeer, The Netherlands, 1996-2005.

(95\% CI 1.04-1.19), $P \leq 0.001$; and HR $=2.02 /(\mathrm{mg} / \mathrm{l})$ (95\% CI 1.41-2.91), $P \leq 0.001$ respectively).

Serum albumin levels just lost their significant relationship with mortality when a multivariate analysis was performed including age, IGFBP 2 , and albumin (HR $=1.1$ year (95\% CI 1.0; 1.1), $P \leq 0.001$, $\mathrm{HR}=2.0 /(\mathrm{mg} / \mathrm{l}) \quad(95 \%$ CI $1.4 ; 3.0), P \leq 0.001$; and $\mathrm{HR}=0.95 /(\mathrm{g} / \mathrm{dl})(95 \% \mathrm{CI} 0.89 ; 1.00), P=0.06$ respectively). Subjects who met the criteria for the low $\mathrm{T}_{3}$ syndrome or nonthyroidal illness did not have a higher mortality risk compared with the other men.

\section{Discussion}

In this prospective study on 403 independently living elderly men, we found that men within the highest quartile of IGFBP 2 concentrations had a twofold higher 8.6-year all-cause mortality compared with men with the lowest IGFBP2 concentrations. In addition, apart from an increased mortality, men with high IGFBP2 levels have, on the one hand, a low physical function, and a deteriorated body composition, including low muscle strength and BMD, and a low somatotropic axis activity, reflected by low IGF1 bioactivity, low IGFBP3 levels, and high IGFBP1 levels. But, on the other hand, men with high IGFBP2 concentrations also had a more favorable metabolic risk profile with a lower BMI, a lower fat mass, and higher insulin sensitivity. However, the proportion of men with the low $\mathrm{T}_{3}$ syndrome, a marker of catabolism is also higher in men with higher IGFBP2 levels. Remarkably, subjects with characteristics of the metabolic syndrome did not have a higher 8-year mortality compared with subjects without the metabolic syndrome. Finally, low physical function, GS, and BMD were also independently associated with higher 8-year mortality.
Several studies have shown that physical performance and muscle strength in older adults inversely predict mortality independent of disease, as recently reviewed in a meta-analysis (27). In our population of elderly men, lower BMD was also significantly associated with mortality independent of disease. Muscle strength and BMD may therefore be a marker for general health.

We previously reported that in this population, low serum IGFBP2 is a strong indicator of overall good physical function as it was strongly inversely related to all measures of functional ability, including BMD and muscle strength in the baseline assessment (12). In this respect, IGFBP2 may serve as a biomarker that integrates parameters of physical function and body composition. The findings of this study pertain to relatively healthy, active old men and may not necessarily apply to a more diseased or obese population. Also, the study had a relatively small sample size and therefore the results require confirmation in a larger population.

However, independent of this association with physical functional status, high circulating IGFBP2 levels were strongly related to a higher 8 -year mortality rate in this relatively healthy population of elderly men, despite the fact that subjects had a more favorable metabolic risk profile. This confirms the findings of $\mathrm{Hu}$ et al. (17) who also found a relationship between higher IGFBP2 levels and increased 6-year mortality in older adults.

IGFBP 2 is the second most abundant binding protein in the circulation. IGFBP 2 is expressed by several tissues including white adipose tissue, liver, and $\mathrm{CN}$ (28). IGFBP2 is regulated by several mechanisms. It decreases after birth until puberty, after which it gradually increases again, especially after the age of 60 years $(29,30,31)$. At 80 years, concentrations are nearly twice as high as in young adults $(0.60 \mathrm{vs} 0.35 \mathrm{mg} / \mathrm{l})$. The precise mechanisms regulating IGFBP 2 concentrations remain unclear, although it is recognized that serum IGFBP2 concentrations are higher during starvation, fasting, and protein restriction, as well as in GH deficiency $(29,32,33)$ and renal failure, $(29)$ and lower in obesity (16). IGFBP2 levels decrease during GH treatment $(14,34)$. In addition, IGF1 appears to be a regulator of IGFBP2, as IGF1 administration increases serum IGFBP2 levels (35), possibly via the suppression of GH secretion (36). Finally, insulin has been proposed as a regulator of IGFBP2 (37).

Both inhibitory and stimulatory effects of IGFBP 2 on IGF actions in vitro have been reported (6). Also, IGFindependent effects of IGFBP 2 on cellular actions in vitro begin to emerge (38). Possibly, the inhibitory role of IGF1 action may play a role in the explanation of the association between IGFBP2 and mortality. Serum IGF1, IGFBP3, and fasting insulin concentrations were inversely related to IGFBP2. In a recent study, we reported that the measurement of biologically active IGF1, rather than immunoreactive IGF1, also predicts mortality (3). IGFBP 2 acts mainly by reducing the IGF 1 
bioavailability (39). Further, insulin affects IGF1 bioactivity mainly through the modulation of IGFBP2 (40). In our group of men, indeed, subjects with high IGFBP 2 concentrations had low circulating IGF1 bioactivity. This relationship was independent of BMI, insulin, and insulin sensitivity.

Further, it has been previously reported that IGFBP2 concentrations in the plasma of cancer patients are significantly higher than those in healthy volunteers (41). In our population, serum IGFBP2 was not related to prostate malignancy or any other form of malignancy at baseline. However, we were not informed about the prevalence of developing malignancies.

In accordance with the previous studies, higher IGFBP2 level was associated with more favorable metabolic risk factors like lower BMI, lower fat mass, higher insulin sensitivity, and a more favorable lipid profile $(17,40)$. In vitro rhIGFBP2 treatment of $3 \mathrm{~T}_{3}$ adipocytes blunted adipogenesis supplemented with hIGF1, suggesting that IGFBP2 inhibits adipogenesis by modulating IGF1 activity (16). However, this potential protective role of IGFBP2 in preventing obesity does not explain the association with an increased mortality. It is more likely that, probably a prolonged period of, catabolism or undernutrition plays a role. As reported earlier, serum IGFBP2 concentrations are higher during starvation, fasting, and protein restriction; conditions that are also associated with nonthyroidal illness. These might explain the links between IGFBP2 levels and nonthyroidal illness in this study, as well as the inverse relationship between IGFBP2 and albumin concentrations. IGFBP2 levels do increase after a prolonged period of fasting (14). It has to be mentioned, however, that only six men in this population were underweight (BMI $<18.5 \mathrm{~kg} / \mathrm{m}^{2}$ ). In contrast to most studies (42), in our population, serum IGF1 or IGF1 bioactivity concentrations were not different between subjects with or without a bad metabolic risk.

Interestingly, the presence of the metabolic syndrome or an elevated BMI in these elderly men was not associated with an impaired survival. This might be due to a selection bias. It may be that men with a strong unfavorable metabolic risk profile had already died. Further, BMI itself may not be a good parameter to assess obesity-related risks (43). In addition, the proportion of men who were obese was small in this population $(n=29)$. On the other hand, other factors play a role in old age. It may be speculated that at younger age, caloric restriction for a certain time leads to a longer life, at least in animals (44). However, having reached a certain age, caloric restriction may be no longer favorable, instead maintaining weight may be more important.

In summary, a high serum IGFBP2 concentration may reflect a catabolic state and is a powerful indicator of a low physical functional status and a worse body composition in these elderly men. In addition, IGFBP 2 levels predict all-cause mortality. Serum IGFBP2 levels may be a biomarker that integrates nutritional status and the biological effects of GH, IGF1, and insulin.

\section{Declaration of interest}

The authors declare that there is no conflict of interest that could be perceived as prejudicing the impartiality of the research reported.

\section{Funding}

This research did not receive any specific grant from any funding agency in the public, commercial or not-for-profit sector.

\section{References}

1 Carter CS, Ramsey MM \& Sonntag WE. A critical analysis of the role of growth hormone and IGF-1 in aging and lifespan. Trends in Genetics 200218 295-301. (doi:10.1016/S0168-9525(02)02696-3)

2 Barbieri M, Bonafe M, Franceschi C \& Paolisso G. Insulin/IGF-Isignaling pathway: an evolutionarily conserved mechanism of longevity from yeast to humans. American Journal of Physiology. Endocrinology and Metabolism 2003285 E1064-E1071. (doi:10. 1152/ajpendo.00296.2003)

3 Brugts MP, Ranke MB, Hofland LJ, van der Wansem K, Weber K, Frystyk J, Lamberts SW \& Janssen JA. Normal values of circulating insulin-like growth factor-I bioactivity in the healthy population: comparison with five widely used IGF-I immunoassays. Journal of Clinical Endocrinology and Metabolism 200893 2539-2545. (doi:10.1210/jc.2007-2454)

4 Hwa V, Oh Y \& Rosenfeld RG. The insulin-like growth factorbinding protein (IGFBP) superfamily. Endocrine Reviews 199920 761-787. (doi:10.1210/er.20.6.761)

5 Baxter RC. Insulin-like growth factor binding proteins in the human circulation: a review. Hormone Research $1994 \mathbf{4 2}$ 140-144. (doi:10.1159/000184186)

6 Jones JI \& Clemmons DR. Insulin-like growth factors and their binding proteins: biological actions. Endocrine Reviews 199516 $3-34$.

7 Jones JI, Gockerman A, Busby WH Jr, Wright G \& Clemmons DR. Insulin-like growth factor binding protein 1 stimulates cell migration and binds to the alpha 5 beta 1 integrin by means of its Arg-Gly-Asp sequence. PNAS $1993 \quad 90 \quad 10553-10557$. (doi:10.1073/pnas.90.22.10553)

8 Perks CM, Vernon EG, Rosendahl AH, Tonge D \& Holly JM. IGF-II and IGFBP-2 differentially regulate PTEN in human breast cancer cells. Oncogene 200726 5966-5972. (doi:10.1038/sj.onc.1210397)

9 Baxter RC, Meka S \& Firth SM. Molecular distribution of IGF binding protein-5 in human serum. Journal of Clinical Endocrinology and Metabolism 200287 271-276. (doi:10.1210/jc. 87.1.271)

10 Firth SM, McDougall F, McLachlan AJ \& Baxter RC. Impaired blockade of insulin-like growth factor I (IGF-I)-induced hypoglycemia by IGF binding protein-3 analog with reduced ternary complex-forming ability. Endocrinology 2002143 1669-1676. (doi:10.1210/en.143.5.1669)

11 Jogie-Brahim S, Feldman D \& Oh Y. Unraveling insulin-like growth factor binding protein-3 actions in human disease. Endocrine Reviews 200930 417-437. (doi:10.1210/er.2008-0028)

12 van den Beld AW, Blum WF, Pols HA, Grobbee DE \& Lamberts SW. Serum insulin-like growth factor binding protein-2 levels as an indicator of functional ability in elderly men. European Journal of Endocrinology 2003148 627-634. (doi:10.1530/eje.0.1480627)

13 Frystyk J, Skjaerbaek C, Vestbo E, Fisker S \& Orskov H. Circulating levels of free insulin-like growth factors in obese subjects: the impact of type 2 diabetes. Diabetes/Metabolism Research and Reviews 199915 314-322. (doi:10.1002/(SICI)1520-7560(199909/ 10) $15: 5<314::$ AID-DMRR 56 > 3.0.CO;2-E)

14 Clemmons DR, Snyder DK \& Busby WH Jr. Variables controlling the secretion of insulin-like growth factor binding protein-2 in normal human subjects. Journal of Clinical Endocrinology and Metabolism 199173 727-733. (doi:10.1210/jcem-73-4-727) 
15 Heald AH, Kaushal K, Siddals KW, Rudenski AS, Anderson SG \& Gibson JM. Insulin-like growth factor binding protein-2 (IGFBP-2) is a marker for the metabolic syndrome. Experimental and Clinical Endocrinology \& Diabetes 2006114 371-376. (doi:10.1055/s2006-924320)

16 Wheatcroft SB, Kearney MT, Shah AM, Ezzat VA, Miell JR, Modo M, Williams SC, Cawthorn WP, Medina-Gomez G, Vidal-Puig A, Sethi JK \& Crossey PA. IGF-binding protein-2 protects against the development of obesity and insulin resistance. Diabetes 200756 285-294. (doi:10.2337/db06-0436)

$17 \mathrm{Hu} \mathrm{D}$, Pawlikowska L, Kanaya A, Hsueh WC, Colbert L, Newman AB, Satterfield S, Rosen C, Cummings SR, Harris TB \& Ziv E. Serum insulin-like growth factor- 1 binding proteins 1 and 2 and mortality in older adults: the Health, Aging, and Body Composition Study. Journal of the American Geriatrics Society 2009 57 1213-1218. (doi:10.1111/j.1532-5415.2009.02318.x)

18 van den Beld AW, Bots ML, Janssen JA, Pols HA, Lamberts SW \& Grobbee DE. Endogenous hormones and carotid atherosclerosis in elderly men. American Journal of Epidemiology 2003157 25-31. (doi:10.1093/aje/kwf160)

19 Guralnik JM, Seeman TE, Tinetti ME, Nevitt MC \& Berkman LF. Validation and use of performance measures of functioning in a non-disabled older population: MacArthur studies of successful aging. Aging 19946 410-419.

20 Guralnik JM, Simonsick EM, Ferrucci L, Glynn RJ, Berkman LF, Blazer DG, Scherr PA \& Wallace RB. A short physical performance battery assessing lower extremity function: association with selfreported disability and prediction of mortality and nursing home admission. Journal of Gerontology 199449 M85-M94.

21 Hamilton A, Balnave R \& Adams R. Grip strength testing reliability. Journal of Hand Therapy $1994 \quad 7 \quad 163-170$. (doi:10.1016/S0894-1130(12)80058-5)

22 Gotfredsen A, Jensen J, Borg J \& Christiansen C. Measurement of lean body mass and total body fat using dual photon absorptiometry. Metabolism 198635 88-93. (doi:10.1016/0026-0495 (86)90101-0)

23 Mazess RB, Barden HS, Bisek JP \& Hanson J. Dual-energy X-ray absorptiometry for total-body and regional bone-mineral and softtissue composition. American Journal of Clinical Nutrition 199051 1106-1112.

24 Folstein MF, Folstein SE \& McHugh PR. "Mini-mental state". A practical method for grading the cognitive state of patients for the clinician. Journal of Psychiatric Research 197512 189-198. (doi:10.1016/0022-3956(75)90026-6)

25 Blum WF \& Breier BH. Radioimmunoassays for IGFs and IGFBPs. Growth Regulation 19944 (Suppl 1) 11-19.

26 Chen JW, Ledet T, Orskov H, Jessen N, Lund S, Whittaker J, De Meyts P, Larsen MB, Christiansen JS \& Frystyk J. A highly sensitive and specific assay for determination of IGF-I bioactivity in human serum. American Journal of Physiology. Endocrinology and Metabolism 2003284 E1149-E1155. (doi:10.1152/ajpendo.00410.2002)

27 Cooper R, Kuh D \& Hardy R. Objectively measured physical capability levels and mortality: systematic review and metaanalysis. BMJ 2010341 c4467. (doi:10.1136/bmj.c4467)

28 Shimasaki S \& Ling N. Identification and molecular characterization of insulin-like growth factor binding proteins (IGFBP-1, 2, -3, -4, -5 and -6). Progress in Growth Factor Research 19913 243-266. (doi:10.1016/0955-2235(91)90003-M)

29 Blum WF, Horn N, Kratzsch J, Jorgensen JO, Juul A, Teale D, Mohnike K \& Ranke MB. Clinical studies of IGFBP-2 by radioimmunoassay. Growth Regulation 19933 100-104.

30 Reeve JG, Schwander J \& Bleehen NM. IGFBP-2: an important regulator of insulin-like growth factor action in human lung tumours? Growth Regulation 19933 82-84.

31 Schwander J \& Mary JL. The RIA for IGFBP-2 in man - a meagre catch? Growth Regulation 19933 104-108.

32 Counts DR, Gwirtsman H, Carlsson LM, Lesem M \& Cutler GB Jr. The effect of anorexia nervosa and refeeding on growth hormonebinding protein, the insulin-like growth factors (IGFs), and the IGF-binding proteins. Journal of Clinical Endocrinology and Metabolism 199275 762-767. (doi:10.1210/jc.75.3.762)
33 Smith WJ, Underwood LE \& Clemmons DR. Effects of caloric or protein restriction on insulin-like growth factor-I (IGF-I) and IGFbinding proteins in children and adults. Journal of Clinical Endocrinology and Metabolism 199580 443-449. (doi:10.1210/ jc.80.2.443)

34 Kassem M, Brixen K, Mosekilde L, Blum WF \& Flyvbjerg A. Effects of growth hormone treatment on serum levels of insulin-like growth factors (IGFs) and IGF binding proteins 1-4 in postmenopausal women. Clinical Endocrinology 199849 747-756. (doi:10.1046/j.1365-2265.1998.00606.x)

35 Zapf J, Schmid C, Guler HP, Waldvogel M, Hauri C, Futo E, Hossenlopp P, Binoux M \& Froesch ER. Regulation of binding proteins for insulin-like growth factors (IGF) in humans. Increased expression of IGF binding protein 2 during IGF I treatment of healthy adults and in patients with extrapancreatic tumor hypoglycemia. Journal of Clinical Investigation 199086 952-961. (doi:10.1172/JCI114797)

36 Carroll PV, Christ ER, Bengtsson BA, Carlsson L, Christiansen JS, Clemmons D, Hintz R, Ho K, Laron Z, Sizonenko P, Sonksen PH, Tanaka T \& Thorne M. Growth hormone deficiency in adulthood and the effects of growth hormone replacement: a review. Growth Hormone Research Society Scientific Committee. Journal of Clinical Endocrinology and Metabolism $1998 \mathbf{8 3}$ 382-395. (doi:10.1210/ jc.83.2.382)

37 Strasser-Vogel B, Blum WF, Past R, Kessler U, Hoeflich A, Meiler B \& Kiess W. Insulin-like growth factor (IGF)-I and -II and IGFbinding proteins- $1,-2$, and -3 in children and adolescents with diabetes mellitus: correlation with metabolic control and height attainment. Journal of Clinical Endocrinology and Metabolism 1995 80 1207-1213. (doi:10.1210/jc.80.4.1207)

38 Wheatcroft SB \& Kearney MT. IGF-dependent and IGF-independent actions of IGF-binding protein-1 and -2: implications for metabolic homeostasis. Trends in Endocrinology and Metabolism 200920 153-162. (doi:10.1016/j.tem.2009.01.002)

39 Rajaram S, Baylink DJ \& Mohan S. Insulin-like growth factor-binding proteins in serum and other biological fluids: regulation and functions. Endocrine Reviews $1997 \mathbf{1 8} 801-831$. (doi:10.1210/er.18.6.801)

40 Arafat AM, Weickert MO, Frystyk J, Spranger J, Schofl C, Mohlig M \& Pfeiffer AF. The role of insulin-like growth factor (IGF) binding protein-2 in the insulin-mediated decrease in IGF-I bioactivity. Journal of Clinical Endocrinology and Metabolism $2009 \mathbf{9 4}$ 5093-5101. (doi:10.1210/jc.2009-0875)

41 Eiseman JL, Guo J, Ramanathan RK, Belani CP, Solit DB, Scher HI, Ivy SP, Zuhowski EG \& Egorin MJ. Evaluation of plasma insulin-like growth factor binding protein 2 and Her-2 extracellular domain as biomarkers for 17-allylamino-17-demethoxygeldanamycin treatment of adult patients with advanced solid tumors. Clinical Cancer Research 200713 2121-2127. (doi:10.1158/1078-0432.CCR06-2286)

42 Akanji AO \& Smith RJ. The insulin-like growth factor system, metabolic syndrome, and cardiovascular disease risk. Metabolic Syndrome and Related Disorders 201210 3-13. (doi:10.1089/met. 2011.0083)

43 Padwal RS, Pajewski NM, Allison DB \& Sharma AM. Using the Edmonton obesity staging system to predict mortality in a population-representative cohort of people with overweight and obesity. CMAJ: Canadian Medical Association Journal 2011183 E1059-E1066. (doi:10.1503/cmaj.110387)

44 Trepanowski JF, Canale RE, Marshall KE, Kabir MM \& Bloomer RJ. Impact of caloric and dietary restriction regimens on markers of health and longevity in humans and animals: a summary of available findings. Nutrition Journal 201110 107. (doi:10.1186/ 1475-2891-10-107)

Received 22 February 2012

Revised version received 17 April 2012

Accepted 3 May 2012 